Itinerari geològic, mineralògic i miner per les comarques de l'Alt Urgell i del Pallars Sobirà: des de la Palanca de Noves a la Guardia d'Ares, Taús, Baen, Useu i al Pont de Bresca

Josep Maria Mata-Perelló

Joaquim Sanz Balagué

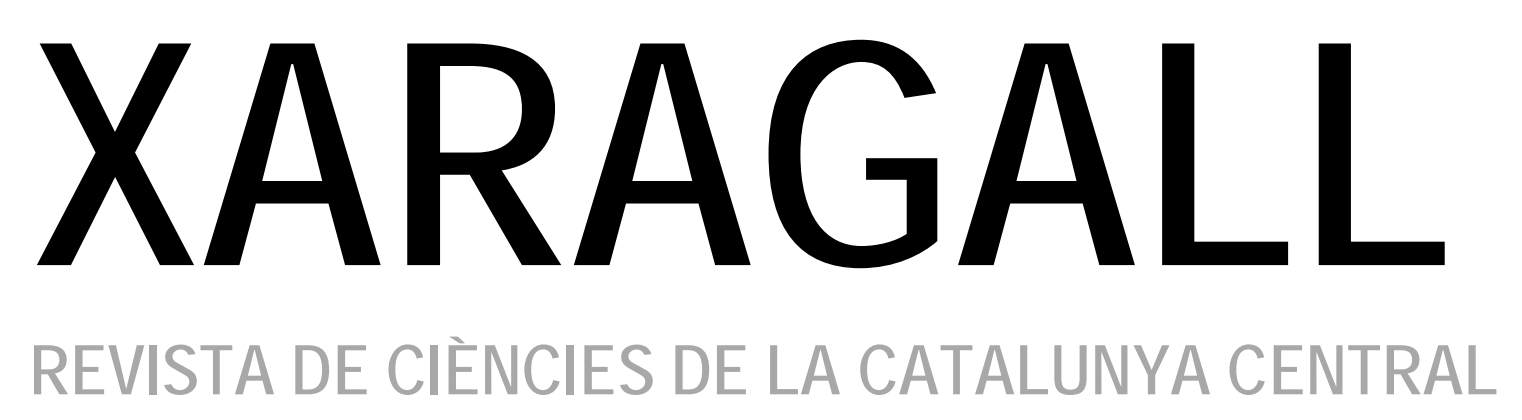

n. 6

JUNY 2015

Com citar l'article: Mata-Perelló, JM.; Sanz Balaguer, J. Itinerari geològic, mineralògic i miner per les comarques de l'Alt Urgell i del Pallars Sobirà: des de la Palanca de Noves a la Guardia d’Ares, Taús, Baen, Useu i al Pont de Bresca. A: XARAGALL. Revista de Ciències de la Catalunya Central. 2015. (n.6). ISSN 2013-4479 DL: B.21483-2009. DOI 


\title{
ITINERARI GEOLÒGIC, MINERALÒGIC I MINER PER LES COMARQUES DE L'ALT URGELL I DEL PALLARS SOBIRÀ: DES DE LA PALANCA DE NOVES A LA GUARDIA D’ARES, TAÚS, BAEN, USEU I AL PONT DE BRESCA
}

\author{
Josep Maria Mata-Perelló \\ Museu de geologia Valentí Masachs, Escola Politècnica Superior d'Enginyeria de Manresa \\ (EPSEM), Universitat Politècnica de Catalunya · BarcelonaTech (UPC), 08272 Manresa, Spain
}

\section{Joaquim Sanz Balagué}

Departament d'Enginyeria Minera i Recursos Naturals (EMRN), Escola Politècnica Superior d'Enginyeria de Manresa (EPSEM), Universitat Politècnica de Catalunya . BarcelonaTech (UPC), 08272 Manresa, Spain

Paraules clau: Sistema Pirinenc, Materials paleozoics, Materials mesozoics, Patrimoni miner

\section{Resum}

Itinerari realitzat el 14 de juliol de $2014^{1}$. La totalitat del recorregut d'aquest itinerari, discorrerà íntegrament entre els afloraments dels materials paleozoics (en bona part del Devonià, del Silurià i de I'Ordovicià; i també del Carbonífer i del Permià) i dels mesozoics (que en bona part pertanyen al Triàsic) del Sistema Pirinenc.

Aquests afloraments es situen dintre del Mantell de Bóixols (situat al Sud del recorregut) i del Mantell de la Zona de les Nogueres (situat als sectors septentrionals del recorregut). És a dir, en tos dos casos, dintre dels geogràficament anomenats Prepirineus

Per d'altra banda, la totalitat del recorregut també discorrerà íntegrament per dues comarques de les que constitueixen l'antiga Regió de la Seu d'Urgell - Tremp; concretament per la de L'Alt Urgell, per on començarà i per del Pallars Sobirà, per on finalitzarà.

\footnotetext{
1 Aquest itinerari és una modificació del recorregut de I'itinerari: ITINERARI GEOLÒGIC, MINERALÒGIC I MINER PER LES COMARQUES DE L'ALT URGELL I DEL PALLARS SOBIRÀ: DES DE LA PALANCA DE NOVES A LA GUARDIA D'ARES I AL PONT DE BRESCA I AL CONGOST DE COLLEGATS / 19B D'OCTUBRE DEL 2013
} 


\section{Objectius fonamentals}

Es concretaran en diversos aspectes, geològics i mineralògics que apuntarem a continuació:

1. Reconeixement dels materials paleozoics del Mantell de la Unitat de les Nogueres, que es tallen entre Malgrat i Gerri de la Sal, pels voltants de la Guardia d'Ares (Alt Urgell). Aquests materials pertanyen segons els indrets al Devonià, Silurià, Ordovicià i Carbonífer; així com al Permià (en realitat del Permotries).

2. Reconeixement dels materials mesozoics del Mantell de la Unitat de les Nogueres i del Mantell de Bóixols, que es tallen inicialment pels voltants de la Palanca de Noves i després pels voltants d'Useu, a diferents trams del recorregut. Aquests materials pertanyen segons els llocs al Triàsic o al Cretàcic, tot i que predominaran els primers.

3. Observació a distància dels materials mesozoics i cenozoics dels relleus prepirinencs de la Unitat Sud-pirinenca Central, que veurem al Sud de recorregut de l'itinerari, en diferents indrets del mateix.

4. Estudi i observació de les estructures del Mantell de la Unitat de les Nogueres i del Mantell de Bóixols, que trobarem a la major part del recorregut de l'itinerari. I tanmateix de les relacions existents entre els dos mantells, per entre els quals discorrerà la totalitat del recorregut de l'itinerari.

5. Reconeixement de diverses mineralitzacions situades fonamentalment a les serres prepirinenques meridionals; com les següents ( $d^{\prime}$ acord amb el sentit de la marxa del recorregut):

$5 A$ ) de les mineralitzacions evaporítiques (fonamentalment de caràcter guixós), situades als termes de Noves de Segre i de Bellpui (a l'Alt Urgell), entre els afloraments triàsics del Keuper

5B) com les mineralitzacions d'alteració associades a afloraments ofítics del triàsic de la Guardia d’Ares, Taús i Useu (Alt Urgell). Aquestes mineralitzacions donaran lloc a la formació d'amiant.

5C) de les mineralitzacions de rebliment de cavitats kàrstiques, situades al terme de Castells, entre els materials carbonatats del Devonià amb minerals de manganès (fonamentalment amb PIROLUSITA),

6. Reconeixement de les explotacions mineres relacionades amb les mineralitzacions de l'apartat anterior.

7. Observació, si s'escau, de les alteracions produïdes sobre el medi natural y sobre el medi ambient per les explotacions anteriors.

8. Observació, si s'escau, dels indrets relacionats amb el Patrimoni Geològic i amb el Patrimoni Miner, que anirem trobant al llarg de tot el recorregut del present itinerari. Dintre d'aquest darrer, farem una observació de les restes de l'antiga Farga de Noves de Segre, la qual es troba situada prop de l'aiguabarreig del Riu de la Guàrdia d’Ares i del Riu de Castellàs. 


\section{Antecedents}

En relació a aquest recorregut, sols coneixem de la existència de dos treballs nostres. Es tracta de MATA-PERELLÓ (1995 i 2005), que segueixen un traçat força semblant en alguns trams del present recorregut. Tret d'aquest no coneixem cap altre antecedent del mateix tipus, que discorri per aquestes contrades. Hi ha un antecedent molt proper a MATA - PERELLÓ (2013), en un itinerari del qual el present, n'és una modificació. Veure la nota (1) de la primera pàgina, al peu de la mateixa.

Pel que fa a les mineralitzacions que veurem en aquest itinerari, cal dir que ja estat prèviament descrites per nosaltres en MATA-PERELLÓ (1990), en un treball de caràcter general, dedicat al conjunt de tota Catalunya.

I pel que fa a l'estructura geològica, ens remetrem a RIBA et altri (1976), i a GUIMERÀ et altri (1992).

Totes aquestes dades bibliogràfiques es podran veure a l'apartat dedicat a les REFERÈNCIES BIBLIOGRÀFIQUES, al qual ens remetem.

\section{Recorregut de l'itinerari}

El recorregut de l'itinerari s'iniciarà a la població de Noves de Segre, tot i que s'haurà començat en realitat a la Palanca de Noves, situada (com l'anterior) dintre de la comarca de I'Alt Urgell.

Des d'aquest indret, per una carretera local (la LV - 5134), s'anirà primer cap a la població de Noves de Segre; i tot seguit cap a les de Bellpui i de Malgrat, sempre dintre de l'Alt Urgell i de les serres prepinenques. En aquest recorregut es faran dues parades més.

Després, i per aquesta mateixa pista - carretera, s'anirà cap a la Guardia d'Ares i Taús, encara situades les dues dintre de I'Alt Urgell. En aquest recorregut s'efectuarà una aturada a la primera població, concretament a les Mines d'Amiant, situades dintre de les Serres Prepirinenques.

Després, i dintre del Mantell de la Zona de les Nogueres, el recorregut continuarà cap a Castells, passant ara a la comarca del Pallars Sobirà. Prop d'aquest darrer poble es farà una breu aturada. 


\section{Advertiments previs}

Com en altres recorreguts de RECERCA GEOLÒGICA I MINERALÒGICA... si es disposa del temps suficient, poden efectuar-se passant per totes les parades i filloles. En cas contrari, recomanem prescindir de les anomenades PARADES - CONDICIONALS.

També recomanem de cercar la informació més adient, sobre els trams a recórrer mitjançant camins de terra, o de pista. En aquest recorregut hi ha un llarg tram que caldrà fer-ho per camins de terra. Es tracta del que va des de Taús fins al Pont de Bresca.

Per altra banda, recomanem tenir una cura extrema de la NATURA, evitant qualsevol forma d'agressió sobre ella, o de fer-n'hi un mal ús del que en ofereix la nostra mare Terra.

\section{Descripció de l'itinerari}

En aquest recorregut hem situat, com ja és habitual en tots els itineraris, una sèrie d'ESTACIONS o de PARADES, que anirem veient a continuació. En cada cas, els hi donarem una denominació que podrà correspondre a algun paratge proper. En aquestes aturades, ens dedicarem a veure diferents elements geològics o mineres, segons s'escaigui.

Per altra banda, en cadascuna de les parades, indicarem entre parèntesi el número del "Mapa Topográfico", a escala 1:50.000, on es troba situada la parada considerada. En aquesta ocasió serà algú dels següents: 252 (o de Tremp) o 253 (o d'Isona).

Així, anirem realitzant les següents aturades, al llarg del recorregut del present itinerari.

\subsection{Parada 1. CAL MATIES (la Palanca de Noves, terme municipal de Noves de Segre, comarca de l’Alt Urgell). (Full 253).}

L'itinerari es comença en aquest indret, situat al costat de I'antiga carretera C-1313, la qual es dirigeix cap a la Seu d'Urgell (en el seu sentit septentrional) i cap a Organyà (en el seu sentit meridional).

A l'indret de la parada es troben uns afloraments dels nivells gresosos i lutítics de color rogenc, que pertanyen al Permotries (o més exactament al Permo-Bunds), que ja es poden incloure dintre del Mantell de la Unitat de les Nogueres. (fotografia 1). 


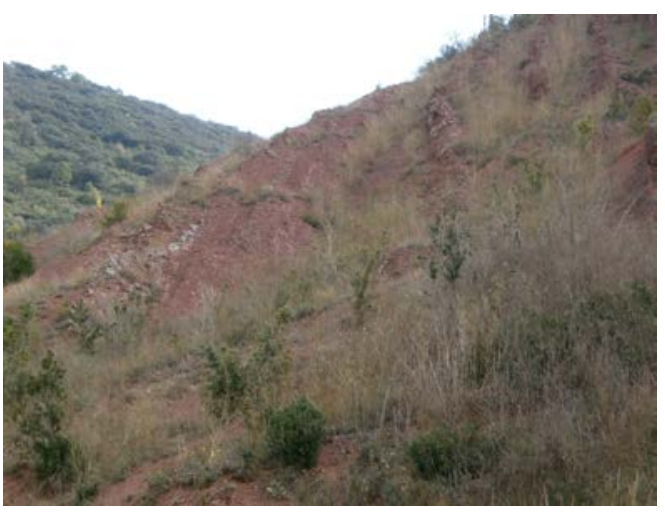

Fotografia 1. Aflorament dels gresos rogencs del Permotries a Can Maties. Octubre 2013

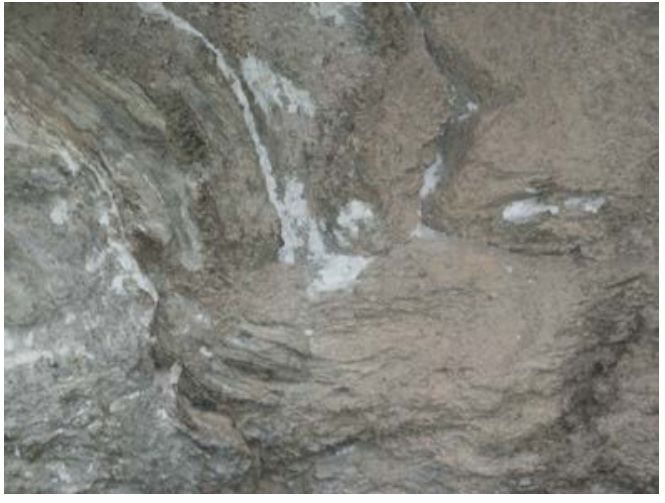

Fotografia 2. Aflorament dels guixos del Keuper a Can Maties. Eflorescències d’EPSOMITA. Octubre 2013

En aquest indret, també apareixen afloraments dels materials del Keuper, amb nivells de guixos, entre els quals es poden veure petits Jacints de Compostel.la. Tanmateix es veuen eflorescències amb EPSOMITA. (fotografia 2).

Cal dir, per altra banda, que una mica més amunt d'on ara som, concretament a la Serra d'Ensenyà, ja hi afloren els terrenys pissarrencs del Carbonífer, que també pertanyen al Mantell de la Unitat de les Nogueres.

\subsection{Parada 2. GUIXERA DE BELLPUI (Bellpui, terme municipal de Noves de Segre - les Valls d'Aguilar, comarca de l’Alt Urgell). (Full 253).}

Després de la parada anterior, cal agafar la carretera local que es dirigeix, des de la C-1313 cap a Noves de Segre. Tot seguit cal continuar per la nova carretera-pista, que se'n va cap a la Guardia d'Ares. Aquesta és la carretera local LV - 5134. Poc després del trencall d'aquesta darrera població s'arriba a una petita guixera, de característiques molt semblants a la de la següent parada. També, es passa per un bon aflorament dels nivells de guixos triàsics del Keuper. Així, haurem efectuat un recorregut proper als $2 \mathrm{Km}$ des de la parada anteriorment realitzada.

En tot aquest breu recorregut, des de la parada anterior, s' han tallat primer els materials rogencs del Permotries constituïts per nivells de gresos i lutites; tot i que aquests es troben coberts, en bona part, pels sediments quaternaris del Riu Segre.

Prop de Noves de Segre, es tornen a tallar els nivells argilosos i guixosos del Keuper, que pertanyen a la Unitat de les Nogueres. Precisament, l'actual parada es troba sobre un aflorament d'aquests darrers nivells, que han estat explotats en aquesta antiga guixera, om ara som. (fotografia 3). 


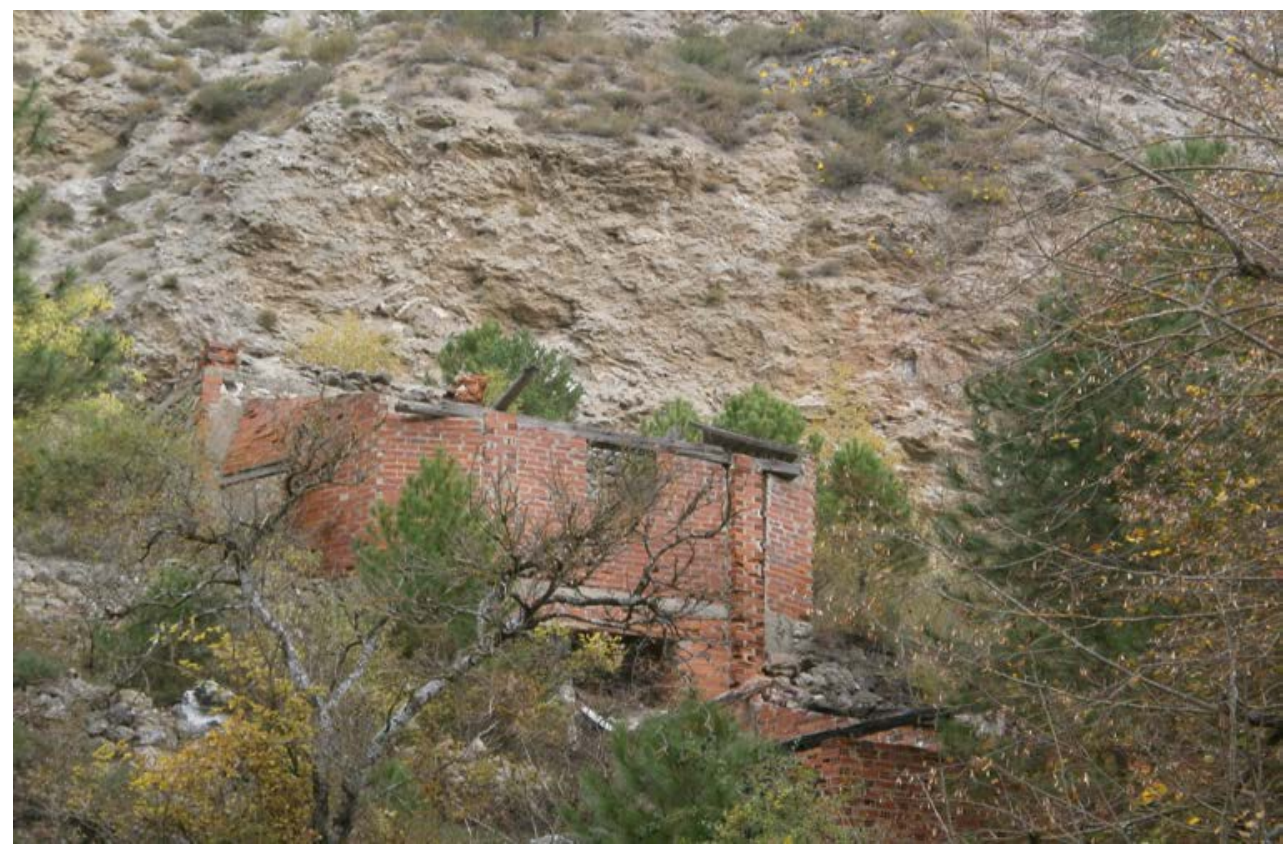

Fotografia 3. Un aspecte de la guixera de Bellpui, amb restes del seu patrimoni miner. Octubre 2013

\subsection{Parada 3 - CONDICIONAL. GUIXERA DE MALGRAT (Malgrat, terme municipal de Noves de Segre - les Valls d'Aguilar, comarca de l'Alt Urgell). (Full 253).}

Des de la parada anterior, caldrà continuar per la carretera que condueix a la Guardia d'Ares, la LV - 5134. En arribar a les immediacions del poble de Malgrat, realitzarem una nova aturada. Així, des de l'anterior, haurem recorregut uns 1'2 Km, aproximadament.

En aquest breu recorregut, des de la parada anterior, s' han continuat tallant els nivells guixosos i argilosos triàsics, que pertanyen al Keuper. Aquests materials pertanyen a la Unitat de les Nogueres. Precisament, l' actual parada es troba sobre un aflorament d'aquests darrers nivells, que han estat explotats en aquesta antiga guixera, om ara som.

Entre els nivells de guixos es troben: ANHIDRITA, HEMIHEDRITA (indicis) i GUIX. També hi ha CALCITA i CAOLINITA.

\subsection{Parada 4. ANTIGA FARGA DE NOVES DE SEGRE, (Malgrat, terme municipal de Noves de Segre - les Valls d'Aguilar, comarca de l'Alt Urgell). (Full 253).}

Des de la parada anterior, caldrà continuar per la carretera que condueix a la Guardia d'Ares, la LV - 5134. Així, anirem remuntant el Riu de la Guàrdia d'Ares. Poc més endavant, després de sobrepassar la Borda d'En Coll, la carretera girarà cap al NW, remuntant ara el Riu de Castellàs. En aquest indret farem una nova aturada, a menys de $1 \mathrm{Km}$ de la parada anterior. Això serà prop del Km 4’ 5 de la carretera.

En arribar a aquest indret, ens caldrà fer un petit recorregut a peu, amb la intenció d'arribar fins al riu, on hi ha un antic edifici..

En aquest recorregut, hem continuat trobant afloraments dels materials esmentats a les aturades anteriors. Tot i així, poc després de Malgrat, haurem començat a trobar afloraments 
dels materials carbonatats del Devonià, que són els que apareixen prop de l'indret de la present aturada.

Pel que fa a l'indret on fem la present aturada, per on afloren les calcàries acabades d'esmentar, cal dir que es tracta de les restes d'una antiga farga catalana, possiblement la més ben conservada de tota la zona, malgrat trobar-se en part coberta de vegetació. En aquesta farga es van utilitzar diversos òxids de ferro, extrets de les proximitats, tot i que no hem pogut localitzar des d'on exactament venien. (fotografies 4 i 5).

Finalment, cal dir que aquestes restes constitueixen un element molt important del Patrimoni Miner i Metal.lúrgic de Catalunya. Igual que les escòries que es troben pels voltants i al mateix edifici, emprats en obres posteriors

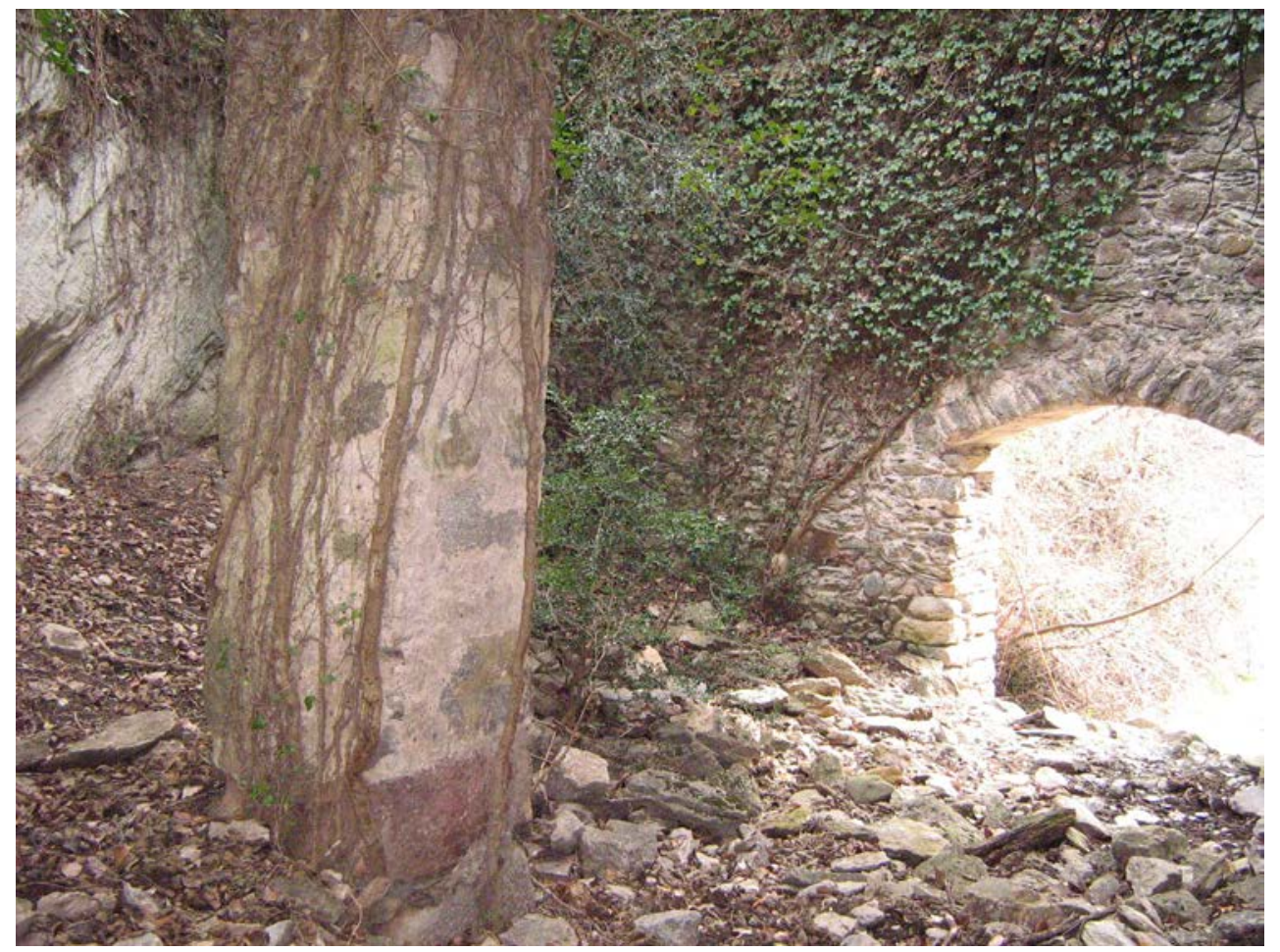

Fotografia 4. Restes de la Farga Catalana de Noves de Segre. Maig del 2006 


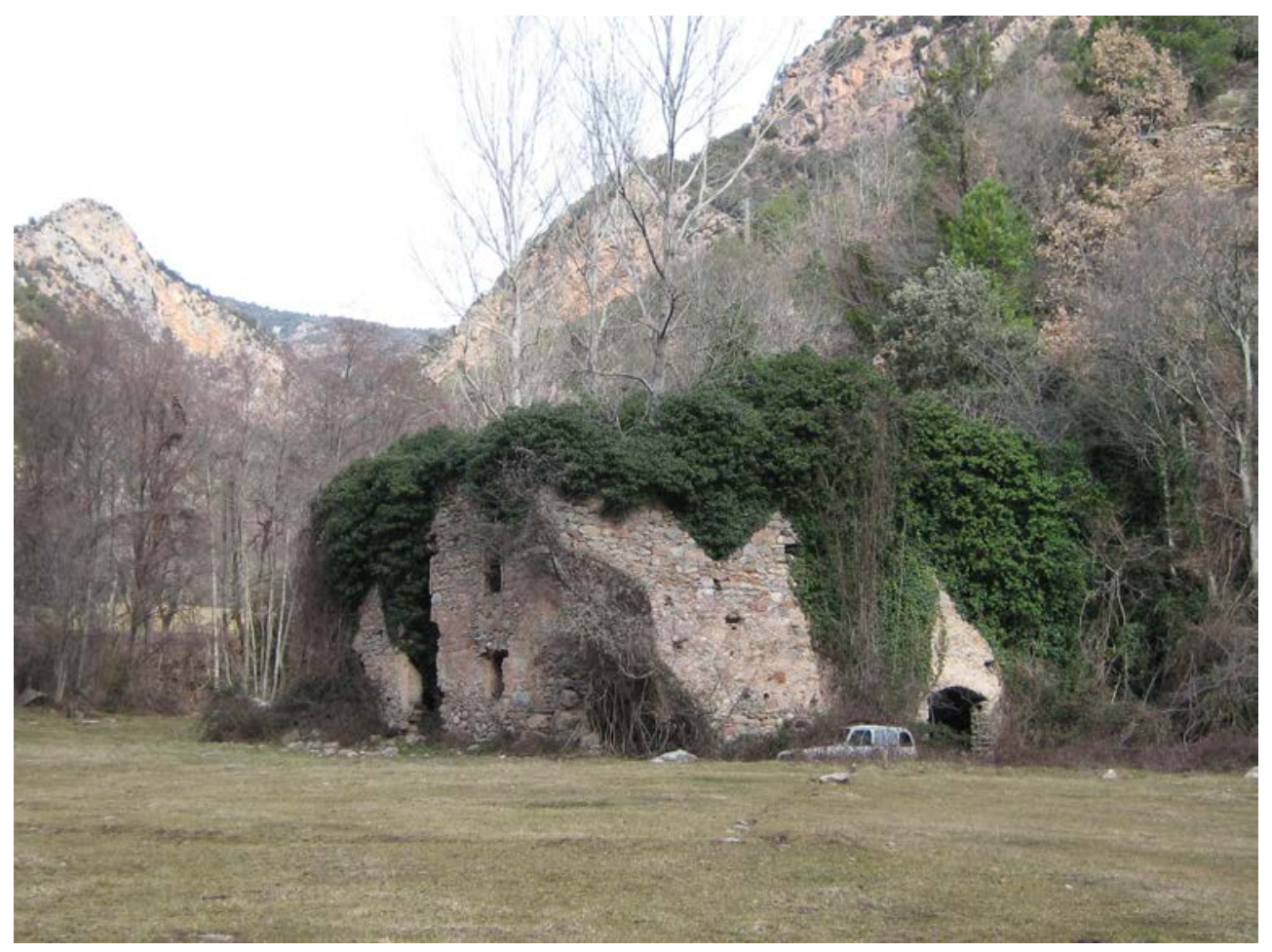

Fotografia 5. Situació de la Farga Catalana, entre els afloraments de les calcàries del Devonià Maig del 2006

\subsection{Parada 5. CARRETERA A LA GUARDIA D’ ARES, PEDRERA DEL COLLET DE MU, (Trejuvell, antic terme municipal de la Guardia d'Ares, i actual del de Noves de Segre - les Vall d’Aguilar, comarca de Alt Urgell). (Full 253).}

Des de la parada anterior, cal continuar per la carretera que es va dirigint cap a la Guardia d'Ares. Inicialment anirem cap el NW, per a girar després del trencall de Castellàs, cap al SW. Després d'una pujada amb moltes corbes es passa prop del poble d'Espaént. Tot seguit, a uns 2 ' $1 \mathrm{Km}$ s'arriba a un collet, per on farem la present aturada, al Collet de Mu. Així, des de la parada anterior, haurem efectuat un recorregut proper als $8 \mathrm{Km}$, aproximadament

En aquest tram, després de la parada, la ruta s'encaixona tot seguint el Riu de Castellàs (just en aquest congost es comencen a tallar els nivells més compactes dels carbonatats de Devonià). En aquest tram, hem seguit la falla de Castellàs, per on baixa el riu del mateix nom.

Passat el congost es troba el trencall de Castellàs, alhora que es troben els nivells esquistosos del Carbonífer. Pel que fa al collet, cal dir que es localitza sobre un aflorament dels nivells gesencs i calcolutítics del Permotries, que s'han començat a trobar a uns 100 metres del collet.

Tot i així, prop del collet, tornem a trobar els materials del Devonià, els quals han estat explotats en una antiga pedrera situada a uns 100 metres de la carretera. (fotografia 6), per ser emprades com a roques ornamental. (fotografia 7 ). 


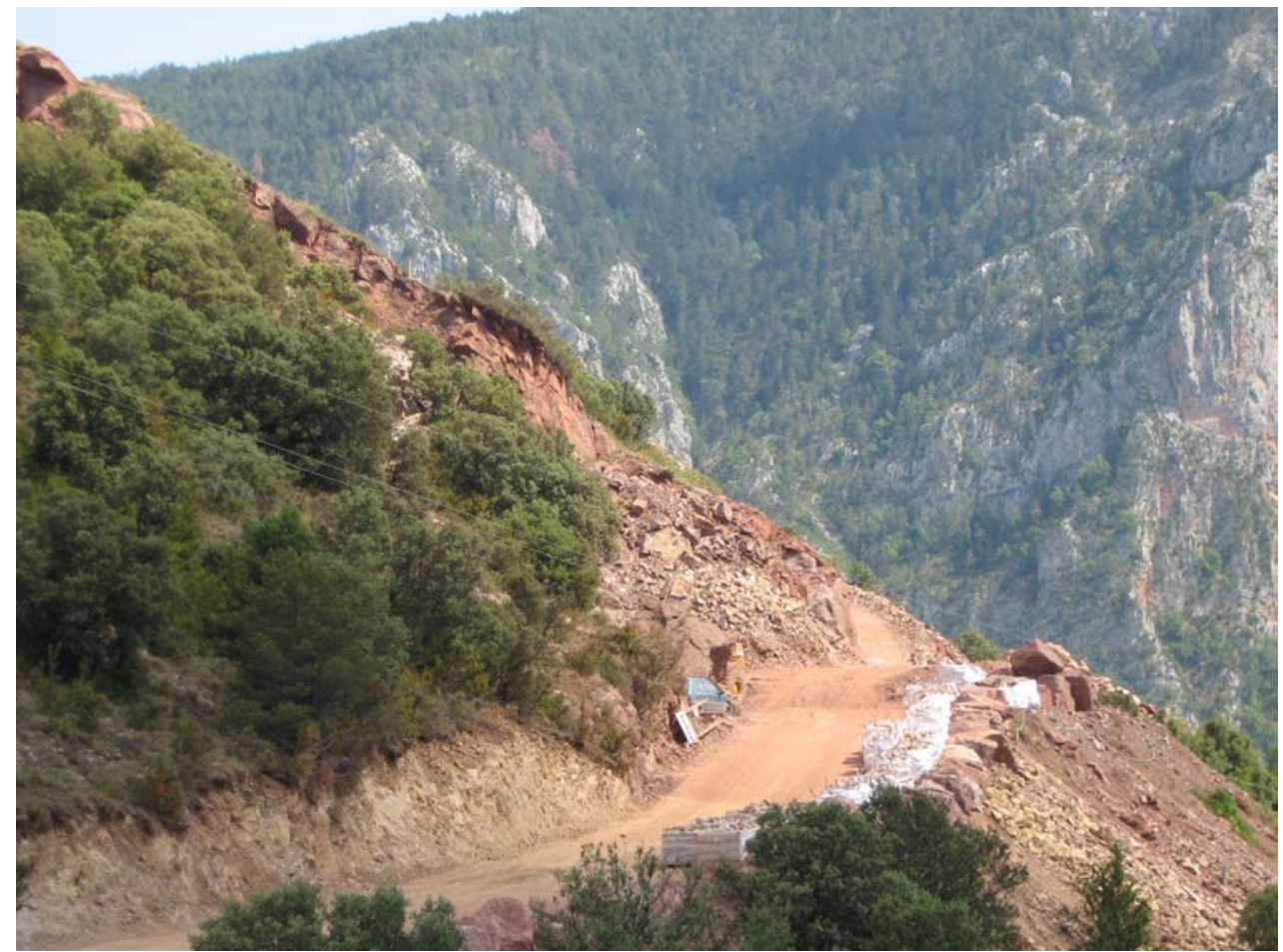

Fotografia 6. Situació de la pedrera, del Collet de Mu, entre els afloraments de les calcàries del Devonià

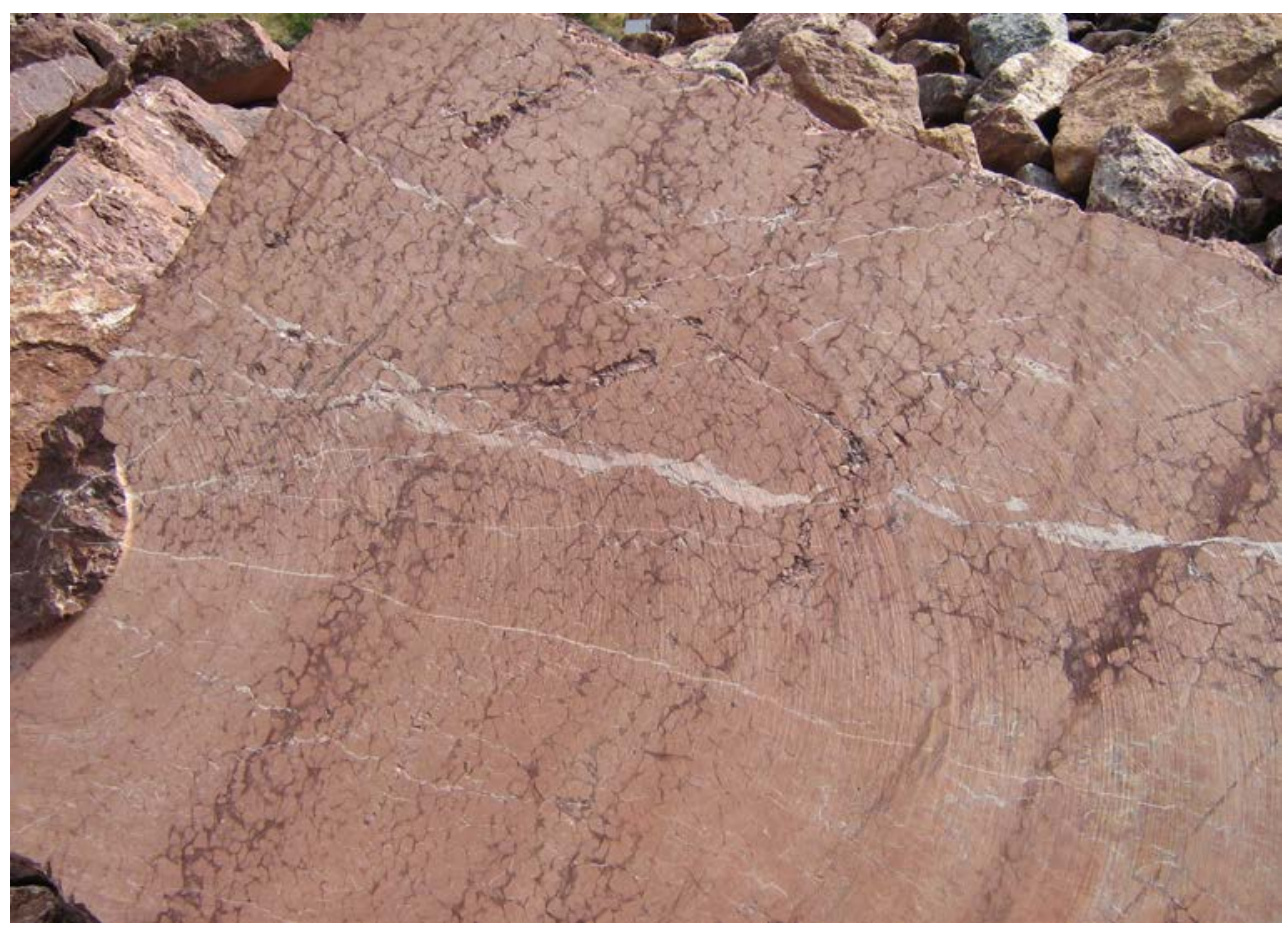

Fotografia 7. Una mostra de les calcàries extretes, polides des de la Palanca de Noves a la Guardia d’Ares, Taús, Baen, Useu i al Pont de Bresca 
Per d'altra banda, des d'aquest indret hi ha la possibilitat de fer una bona observació dels afloraments de les calcàries del Devonià, situades a l'altra banda del riu Castellàs. Aquest calcaries formen part dels relleus de Sant Quirze, per on situa l'ermita d'aquest sant. (fotografía 8).

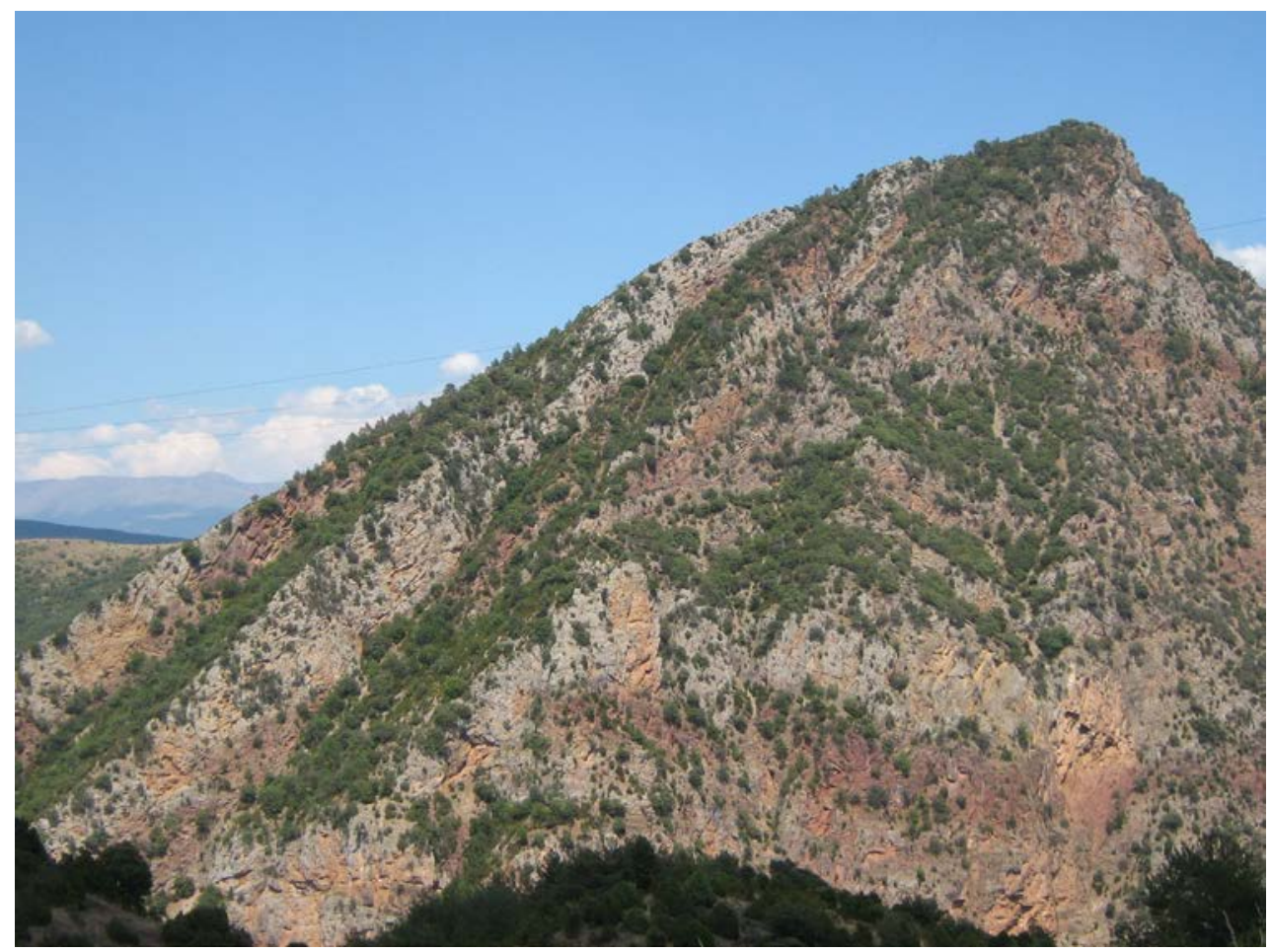

Fotografia 8. Situació de la pedrera, del Collet de Mu, entre els afloraments de les calcàries del Devonià

Així, des d'aquest indret, es pot gaudir d'una bona situació d'observació, tot mirant cap a l'Est (cap al cim de l'Ermita de Sant Quirze). Així, es pot veure l'encavalcament dels materials del Devonià i del Carbonífer, sobre els terrenys triàsics, eminentment del Keuper, que es troben a la fons de la vall.

Tots aquests materials acabats d'esmentar, pertanyen a la Unitat del Mantell de les Nogueres, i es continuaran trobant fins arribar als voltants de Gerri de la Sal. 


\subsection{Parada 6. EL TARTER DEL MANAIRONS, (antic terme de la Guardia d'Ares, i actualment del de Noves de Segre - les Valls d'Aguilar, comarca de l'Alt Urgell). (Full 253).}

Des de la parada anterior, cal continuar cap a la Guardia d'Ares, tot passant per Trejuvell i més endavant per Ausiàs, seguint sempre la carretera local LV - 5134. Poc després de passar per la primera població esmentada, anant cap a Taús, es troba un camí a l'esquerra, que baixa cap el riu de la Guàrdia d'Ares. Ens caldrà agafar-lo. Aquest camí, despès de sobrepassar el riu, ens porta cap a l'Obaga de la Guàrdia, per on es troben els menairons. En arribar-hi, farem una nova aturada a uns $2-3 \mathrm{Km}$ del poble i a uns $9-10 \mathrm{Km}$ de la parada anterior.

En el recorregut seguit, de la parada anterior, s'han continuat trobant els materials del Mantell de la Unitat de les Nogueres, tant els del Devonià, com els del Carbonífer, o els del Permotries. Cap a les immediacions de la Guardia d'Ares es torna a passar als afloraments triàsics del Keuper. Per d'altra banda, hem circulat sempre pel bloc aixecat de l'encavalcament del Mantell de la Unitat de les Nogueres, sobre el Mantell de Bóixols, que es situa al Sud de la Guàrdia d'Ares. Tot i així, ara hem entrat a aquest darrer mantell i ens trobem entre afloraments dels materials carbonatats del Juràssic i del Cretàcic.

En aquests indrets hi ha un típic relleu periglacial, constituït pels anomenats Tarters dels Manairons (o Minairons). Es tracta d'un conjunt de blocs, fragmentats que formen un gran Pedregal. Aquests blocs tenen un cert moviment, formant uns rius de pedres. Els blocs es desplacen en intercalar-se aigua en els espais vuits. Després, en gelar-se l'aigua, augmenta el seu volum, aixecant els blocs i fent-los caure en la direcció de la màxima pendent. Així, aquests tarters tenen un cert desplaçament cap avall, però molt lent. Aquest desplaçament ha produït I'amuntegament de blocs, els quals es localitzen a diferents indrets situats al Sud de la Guàrdia d'Ares, anomenant-se tarters dels Manairons. Els blocs estan formats per fragments de diverses roques, de calcaries cretàciques, juràssiques i també dels nivells de conglomerats del Permotries.

Aquesta disposició ha donat peu a la coneguda llegenda dels manairons, una espècie de follets, que per les nits amuntegaven aquestes roques, treballant pel seu amo. Vivien en un canut i demanaven treball al seu amo, del contrari I'acabarien matant. En fi es tracta d'una antiga llegenda, estesa per diferents indrets dels Pirineus.

Tot i així, la raó geològica, de l'amuntegament és la que hem dit anteriorment, tractant-se de fenòmens típicament periglacials. (fotografia 9). 


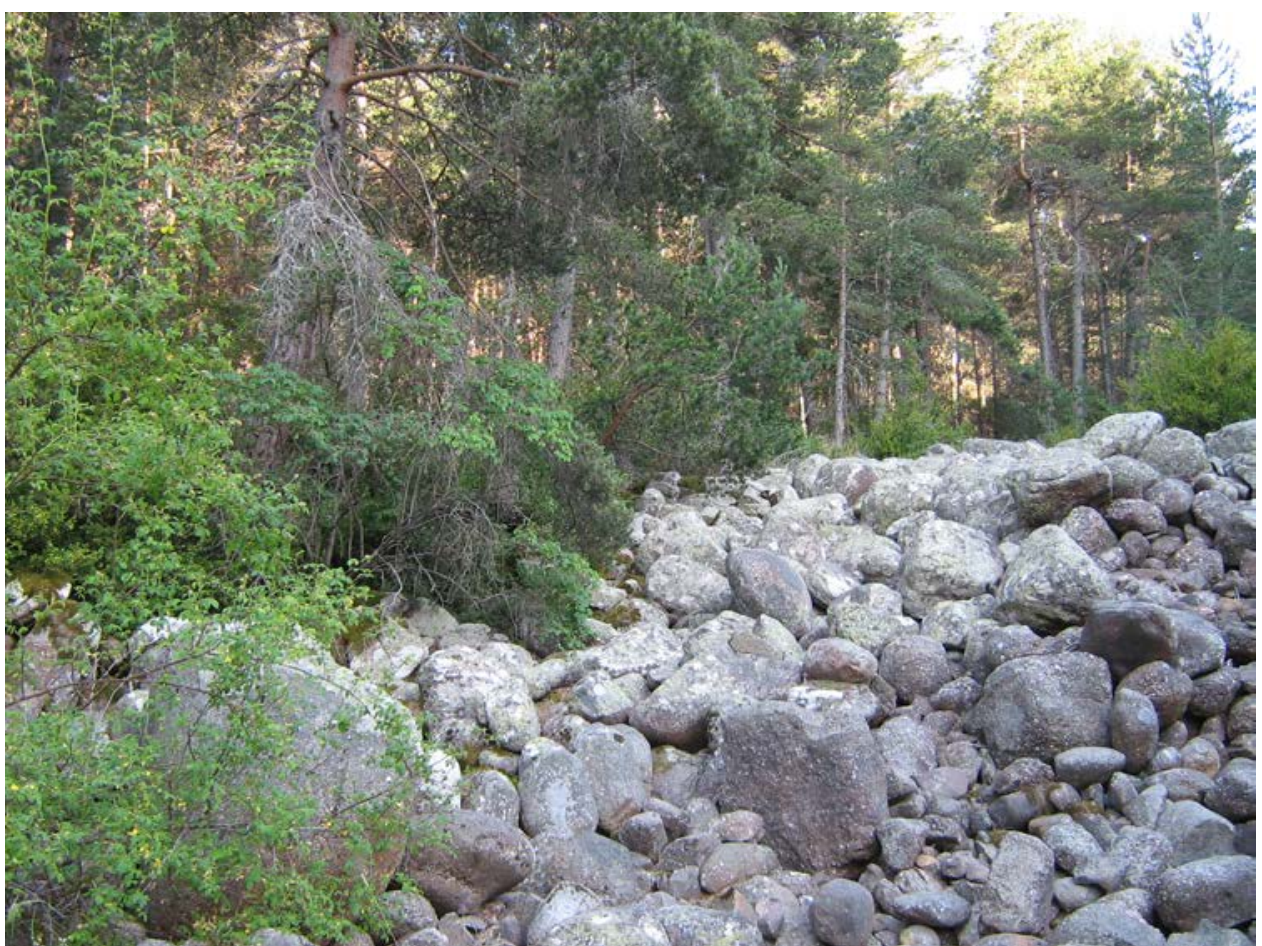

Fotografia 9. Un dels Tartes dels Manairons de la Guàrdia d'Ares

\subsection{Parada 7. MINA D'AMIANT DE LA GUÀRDIA D'ARES, (antic terme de la Guardia d'Ares, i actualment del de Noves de Segre - les Valls d'Aguilar, comarca de l'Alt Urgell). (Full 253).}

Després de realitzar l'aturada anterior, cal retornar cap el poble la Guardia d'Ares. Quasi en arribar, en trobar la carretera local LV - 5134, ens caldrà agafar-la en el seu sentit cap el poble de Taús. A menys de $1 \mathrm{Km}$ d'haver-la trobat, ens caldrà agafar un corriol per l'esquerda que condueix cap a l'antiga Mina d'Amiant, la qual es troba a l'esquerra de la carretera, situant-se a quasi $1,5 \mathrm{Km}$ del primer poble anteriorment esmentat, de la Guàrdia d'Ares.. Així, des de la parada anterior, haurem fet un recorregut proper als $4-5 \mathrm{Km}$.

En aquest recorregut, hem tornat a trobar els materials esmentats anteriorment, Així, haurem sobrepassat l'encavalcament i ens tornarem a situar dintre de la Unitat del Mantell de les Nogueres. Així, fonamentalment, haurem trobat afloraments del Devonià i del Permotries.

Tot i així, a l'indret de l'aturada hi havia una antiga explotació minera. El ella s'explotava una mineralització associada a un aflorament de les ofites del Keuper. Per alteració d'aquestes, s'han format: CLINOZOISITA, EPIDOTA i TREMOLITA. Els amiants, s' han format a partir del darrer mineral. També, hi ha CALCITA i CAOLINITA. (fotografia 10).

Pel que fa al Patrimoni Miner, cal dir que es poc important, limitant-se a les tremuges on es carregava el material estret i a les explotacions. (fotografia 11). 


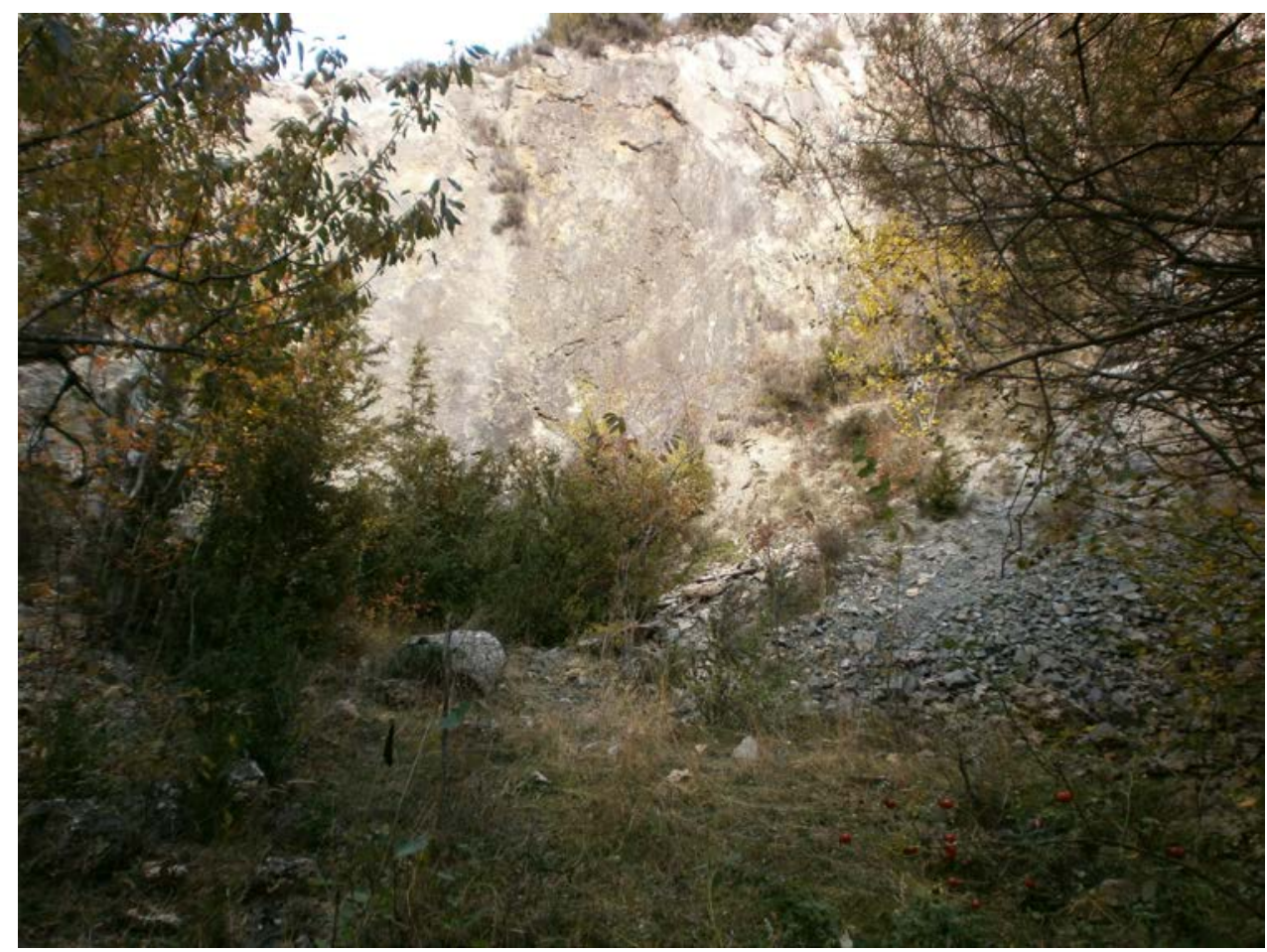

Fotografia 10. Un aspecte del front d’explotació de la pedrera d'amiant de la Guàrdia d'Ares. Octubre 2013

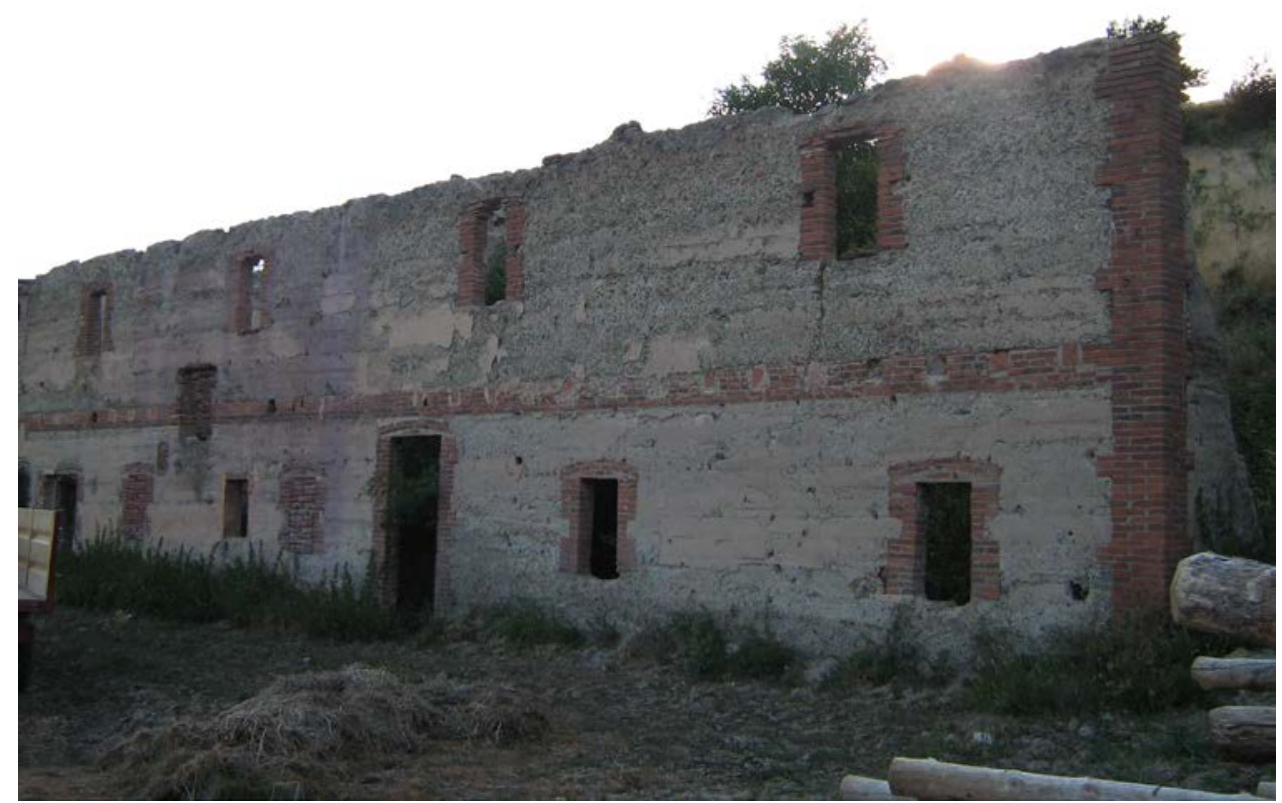

Fotografia 11. Restes de les explotacions mineres de la Mina d’Amiant de la Guàrdia d’Ares. Tremuges Octubre 2013 des de la Palanca de Noves a la Guardia d’Ares, Taús, Baen, Useu i al Pont de Bresca 


\subsection{PARADA 8 - CONDICIONAL. BARRANC CANALÉS (antics termes de la Guardia d'Ares i de Taús, actualment del de Noves de Segre - les Valls d'Aguilar, comarca de I’Alt Urgell). (253).}

Des de la parada anterior, cal continuar cap a Taús. A molt poca distància de l'indret anterior, i abans d'arribar al poble, cal fer una nova aturada, a quasi $1 \mathrm{Km}$ i escaig de la darrera aturada.

En aquest recorregut, hem continuat trobant els materials triàsics del Mantell de la Zona de les Nogueres, que ja hem esmentat a la parada anterior. Precisament, aquests són els materials que apareixen al mateix indret de l'aturada.

En aquest indret es troba un altre aflorament similar al de la parada anterior, situat al Barranc Canalés (antic terme de la Guardia d'Ares). A tocar d'aquest indret, però una més endavant, a la Vall (dintre de l'antic terme de Taús), es troba una mineralització similar.

\subsection{Parada 9 - CONDICIONAL. SAUQUET (els Castells, antic terme municipal de Taús, actualment del de Noves de Segre - les Valls d'Aguilar, comarca de I’Alt Urgell). (Full 253).}

Després de les mines d'amiant visitades, caldrà continuar primer cap a Taus, seguint sempre per la carretera local LV - 5134. Després d'arribar al poble acabat d'esmentar, ens caldrà seguir cap a Castells. Després caldrà seguir cap a Sant Sebastià. Poc després de la primera població es troba l'indret de Sauquet, situat al costat de la pista (cal dir que a Els Castells, la carretera es converteix en una pista de terra). Aquí farem una nova aturada, a uns $9 \mathrm{Km}$ de la parada anterior.

En aquest petit recorregut, des de la parada anterior, es tornen a la tallar els materials calcaris del Devonià, que pertanyen a la Formació Compte, i que s'inclouen dintre de la Unitat de les Nogueres. Cap els voltants de Castells, es comencen a tallar els nivells pissarrencs del Carbonífer, que s' inclouen dintre de la mateixa unitat. Aquests materials van alternant amb els anteriors, dintre del recorregut.

En aquest indret, i dintre dels afloraments calcaris del Devonià, es troba una mineralització manganesífera de rebliment de cavitats d'origen kàrstic. Entre els minerals de Mn presents cal parlar de la presència de: BIRNESSITA, PIROLUSITA, PSILOMELANA. Amb ells, també es troben mineralitzacions de ferro amb GOETHITA (limonítica) i HEMATITES. Altres minerals presents a l'indici són: CALCITA i DOLOMITA.

\subsection{Parada 10. BARRANC DE GAVARRET (Sarroca, antic terme de Baén, $i$ actualment del de Gerri de la Sal - Baix Pallars, comarca del Pallars Sobirà). (Full 352).}

Després de realitzar la parada anterior, cal continuar per la pista de terra, que ara va conduint cap a Baén. Així, primer anirem, sempre cap a ponent, cap al Coll de les Iglésies (també anomenat Coll Negre). En sobrepassar-lo deixarem I'Alt Urgell per entrar al Pallars Sobirà. Després, de sobrepassar el coll, baixarem cap el barranc de Gavarret, per on farem una nova aturada. Així, des de la parada anterior, haurem efectuat un recorregut proper als $5-6 \mathrm{Km}$. Cal dir que aquesta pista no es troba gairebé, especialment a l'hora de sobrepassar el coll.

En aquest recorregut, hem començat trobant afloraments dels materials del Devonià. Posteriorment, en arribar al coll, haurem trobat els nivells negres de les pissarres carbonoses del Silurià, que provoquen la formació de nombrosos aiguamolls. Després, la ruta comença a 
baixar cap al Barranc de Gavarret, però es torna a discorre entre els materials calcaris del Devonià.

En arribar a les immediacions del pont sobre el Barranc Gavarret, es tornen a tallar els materials del Silurià. Cal dir que aquest indret es troba per sota del coll anteriorment esmentat.

En aquesta ocasió, entre els nivells de pissarres carbonoses, es troba PIRITA, que per alteració ha produït la formació de: MARCASSITA, MELNIKOWITA, GOETHITA (limonítica), LEPIDOCROCITA, HALOTROIQUITA, MELANTERITA i SIDEROTÍL, entre altres minerals d’oxidació. (fotografia 12).

També cal dir que en aquest tram del recorregut, es van trobant abundants restes fòssils entre els materials del Silurià. Així es van trobant ortthoceres, entre altra fauna del Silurià. (fotografia 13).

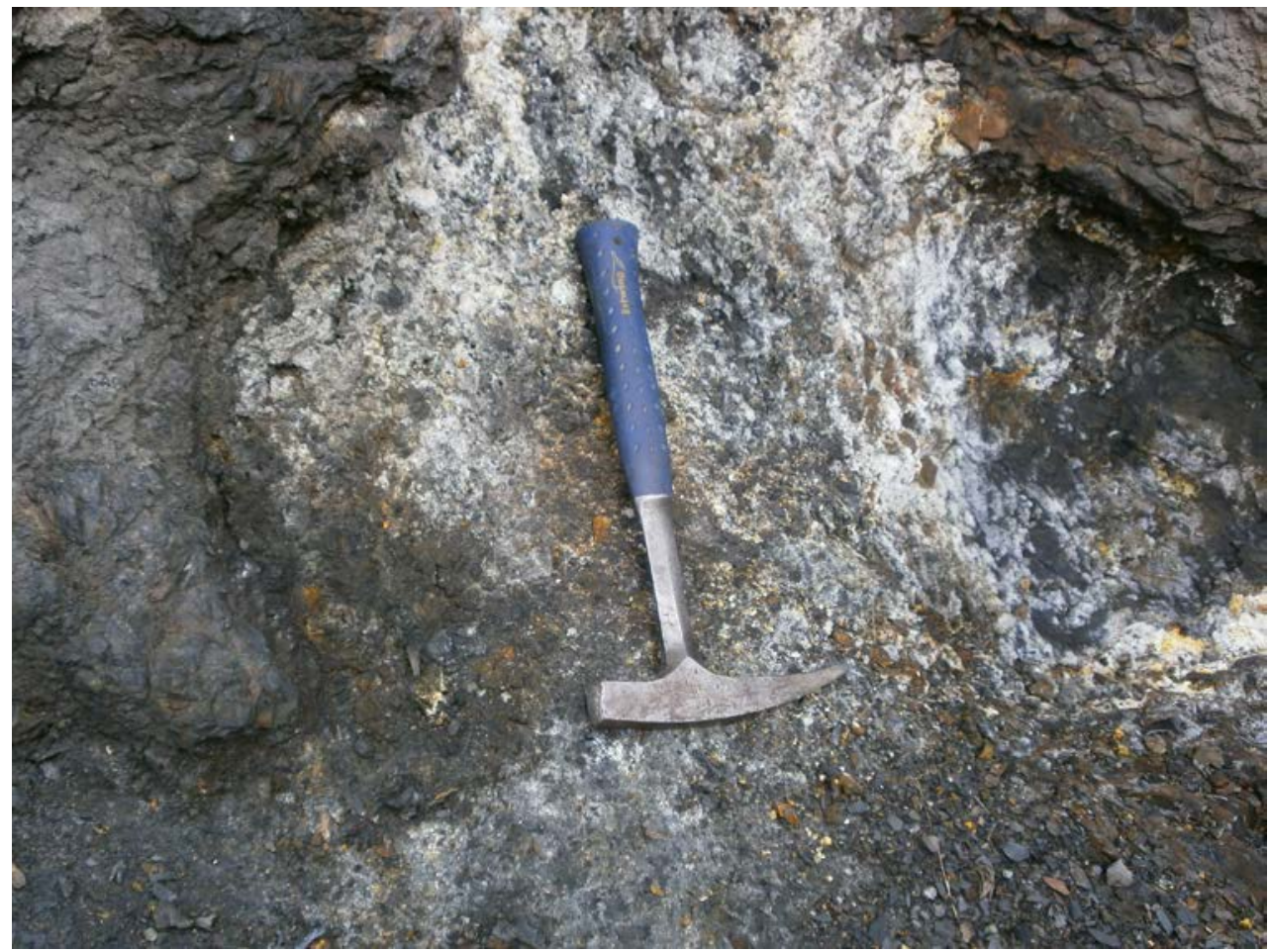

Fotografia 12. Eflorescències amb sulfats de ferro (HALOTROIQUITA, MELANTERITA, SIDEROTIL), entre els materials del Silurià. Barranc de Gavarret. Octubre 2013 


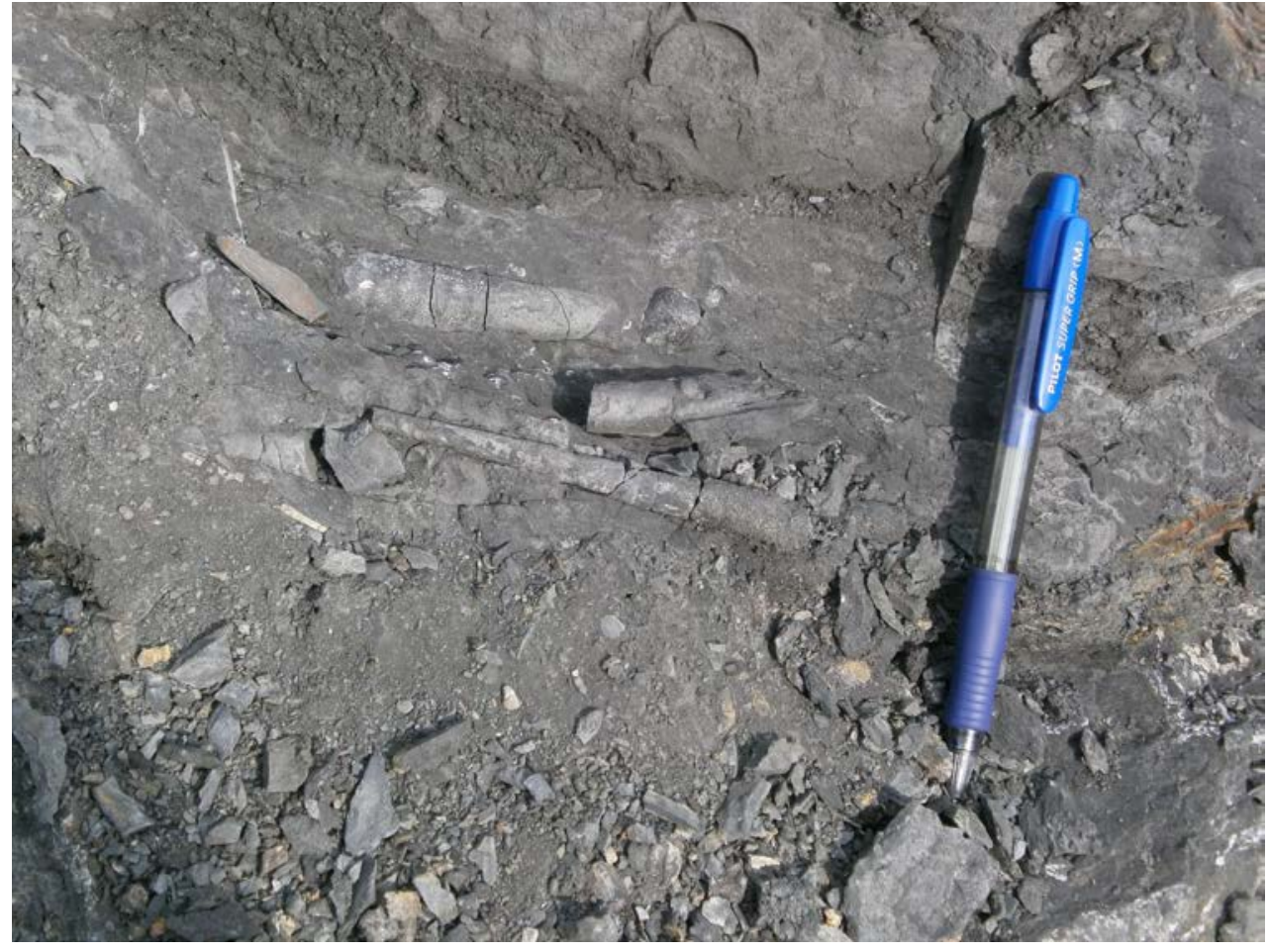

Fotografia 13. Restes de Orthoceres, entre els materials del Silurià. Barranc de Gavarret. Octubre 2013

\subsection{Parada 11. IMMEDIACIONS DE BUSEU, ROCALLERS, (Buseu, antic terme de Baén, actual de Gerri de la Sal - Baix Pallars). (Full 252).}

Tot continuant per la pista-carretera, cap a Baén, es passa primer per la Masia de Sarroca (Sant Roc de Sarroca), a parir de la qual millora molt el camí. Tot seguit, deixarem per la dreta el trencall que es dirigeix cap a Sant Sebastià de Buseu i ens anirem apropant cap al poble de Buseu. Poc abans d'arribar-hi, prop del trencall (per I'esquerra) de Rocallers, farem una nova aturada Així, des de la parada anterior, ens haurà calgut fer un desplaçament proper als $6 \mathrm{Km}$, per tal d'arribar fins a l'indret on ara sens trobem situats.

En aquest trajecte, segons els indrets, es van trobant els materials del Silurià, Devonià, i Carbonífer, que pertanyen al Mantell de la Unitat de les Nogueres. Poc abans d'arribar a I'indret de I'aturada haurem trobat aflorament dels materials del Permotries. Com al llarg de tot el recorregut, estem situats dintre del Mantell de les Nogueres.

Des d'aquest indret, mirant cap el NE (cap l'antic poble de Castellnou), podem veure unes interessants estructures, entre els afloraments dels materials carbonatats del Devonià, que formen part de la Serra de Mollet i dels relleus de les Piques. Es tracta del flanc d'un anticlinal que encavalca cap el Sud. (fotografia 14). 
Per altra banda, mirant cap el Sud d'on ara ens trobem, podem veure el tall del Riu Major (que procedeix de Taus i es dirigeix cap el Pont de Bresca, per on desemboca al Noguera Pallaresa). En mirar-lo, podem veure en primer terme, els materials carbonatats del Devonià, del formant uns interessant hock-baks. (fotografia 15).

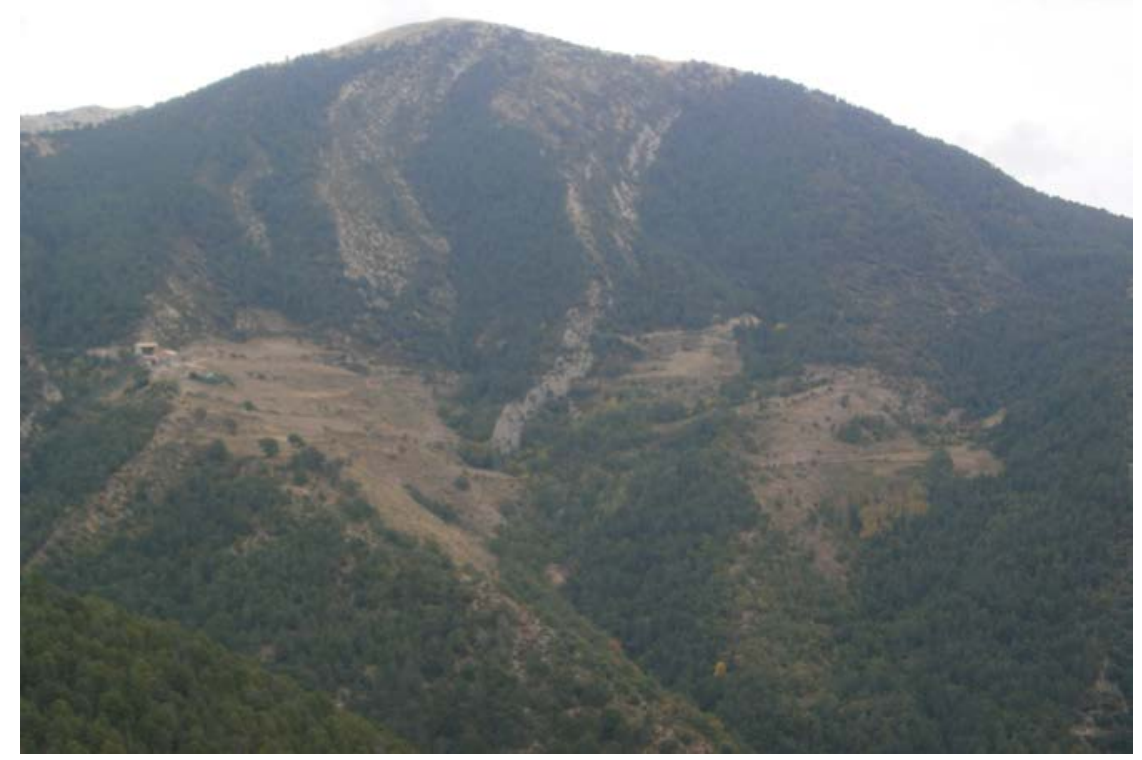

Fotografia 14. Front d'encavalcament dels materials del Devonià de la Serra de Mollet. Octubre 2013

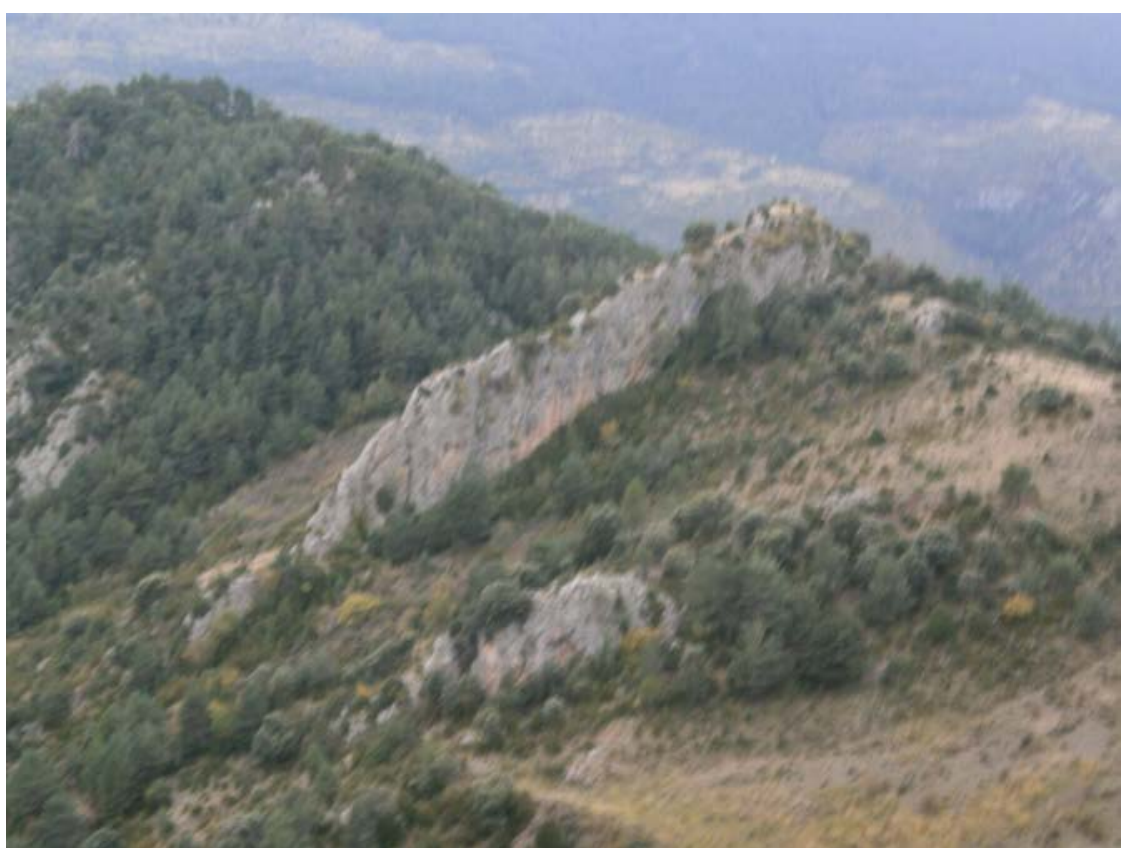

Fotografia 15. Front d'encavalcament dels materials del Devonià del Mantell de les Nogueres sobre el Mantell de Bóixols, prop de Rocallers i per sobre del Riu Major.

Octubre 2013 des de la Palanca de Noves a la Guardia d’Ares, Taús, Baen, Useu i al Pont de Bresca 


\subsection{Parada 12. CARRETERA A GERRI DE LA SAL, PEDRERA DE LES IMMEDIACIONS DEL TRENCALL D'USEU (Useu, antic terme de Baén, actual de Gerri de la Sal - Baix Pallars). (Full 252).}

Tot continuant per la carretera, cap a Buseu i cap a Baén. S'arribarà aviat al trencall del primer poble. Posteriorment, per la pista s'arribarà al poble de Baén, l'antiga capital municipal d'aquesta zona. Després, ens caldrà anar cap a les immediacions del trencall d'Useu. Poc abans d'arribar-hi, trobarem una pedrera al costat de la carretera, per on farem una nova aturada, a uns $4 \mathrm{Km}$ de l'anterior.

En aquest trajecte, segons els indrets, es van trobant els materials que pertanyen al Mantell de la Unitat de les Nogueres. Poc abans d'arribar a Baén, es comencen a trobar els nivells rogencs del Permotries, i més avall ja es troben els del Keuper. Tanmateix veurem afloraments dels materials carbonatats del Triàsic Mig, del Muschelkalk, com a I'indret de la present aturada, on van ésser explotats per a l'obtenció d’àrids. (fotografia 16).

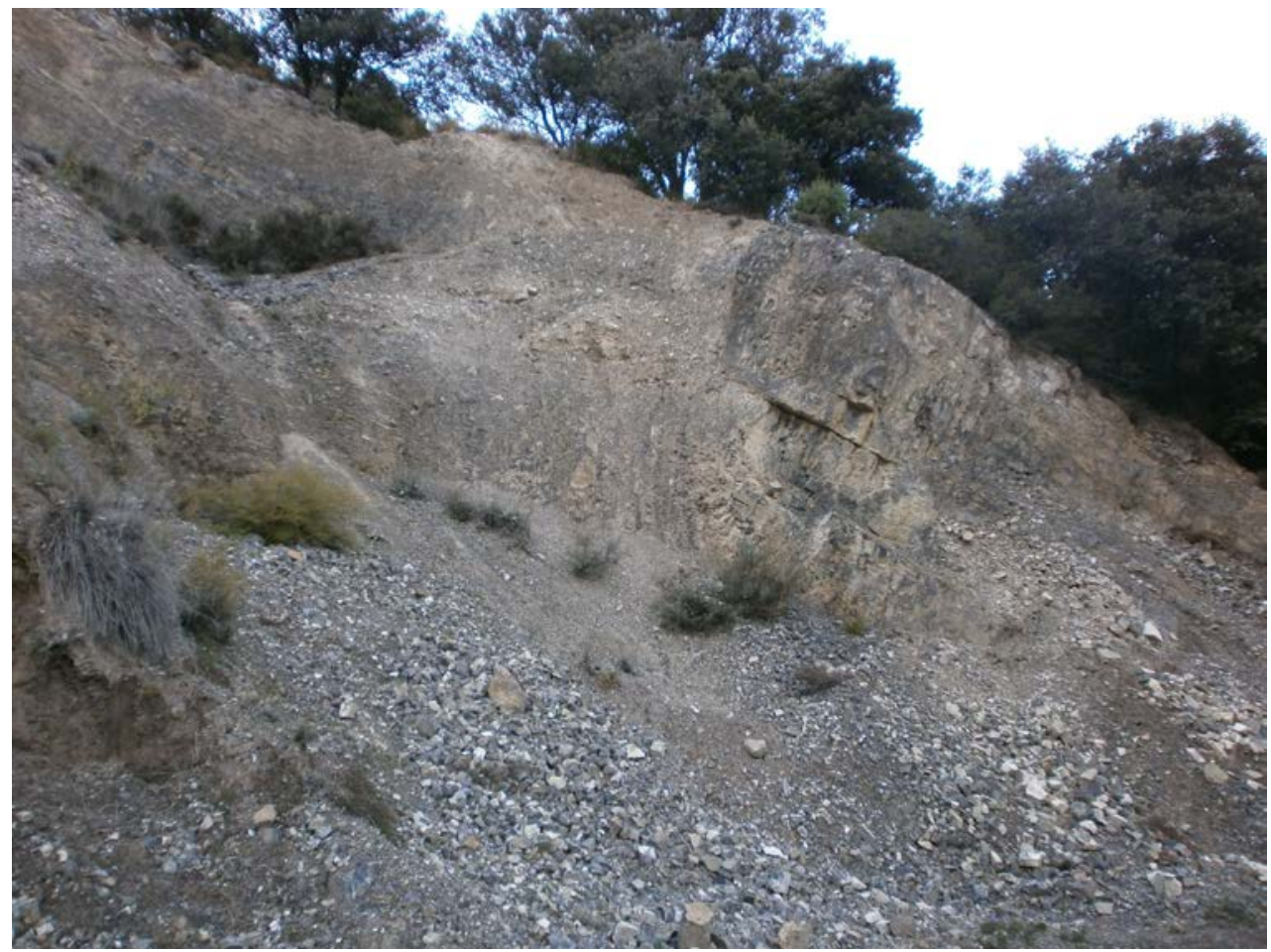

Fotografia 16. Pedrera oberta sobre un aflorament de les calcàries del Muschelkalk. Immediacions d'Useu. Octubre 2013 


\subsection{Parada 13. TRENCALL D’USEU (Useu, antic terme de Baén, actual de Gerri de la Sal - Baix Pallars). (Full 252).}

Després de fer l'aturada anterior, cal continuar cap al trencall d'Useu. En arribar-hi, farem una nova aturada, a poc menys de $1 \mathrm{~km}$ des de l'anterior parada.

En aquest recorregut, hem continuat trobant els materials esmentats als recorreguts anteriors, especialment els materials triàsics del Keuper, dintre del Mantell de les Nogueres, on ens trobem situats., tot i que molt prop de l'encavalcament d'aquest mantell sobre el Mantell de Bóixols.

En efecte, ara ens trobem al Nord del Riu Major, que en bona part discorre per la zona de contacte entre els dos mantells. Aquest riu, de molt sovint va encaixonat entre els materials carbonats del cretàcics del darrer mantell esmentat. Així, des d'aquesta posició es pot veure aquest encaixonament, prop del poble d'Useu. (fotografia 17).

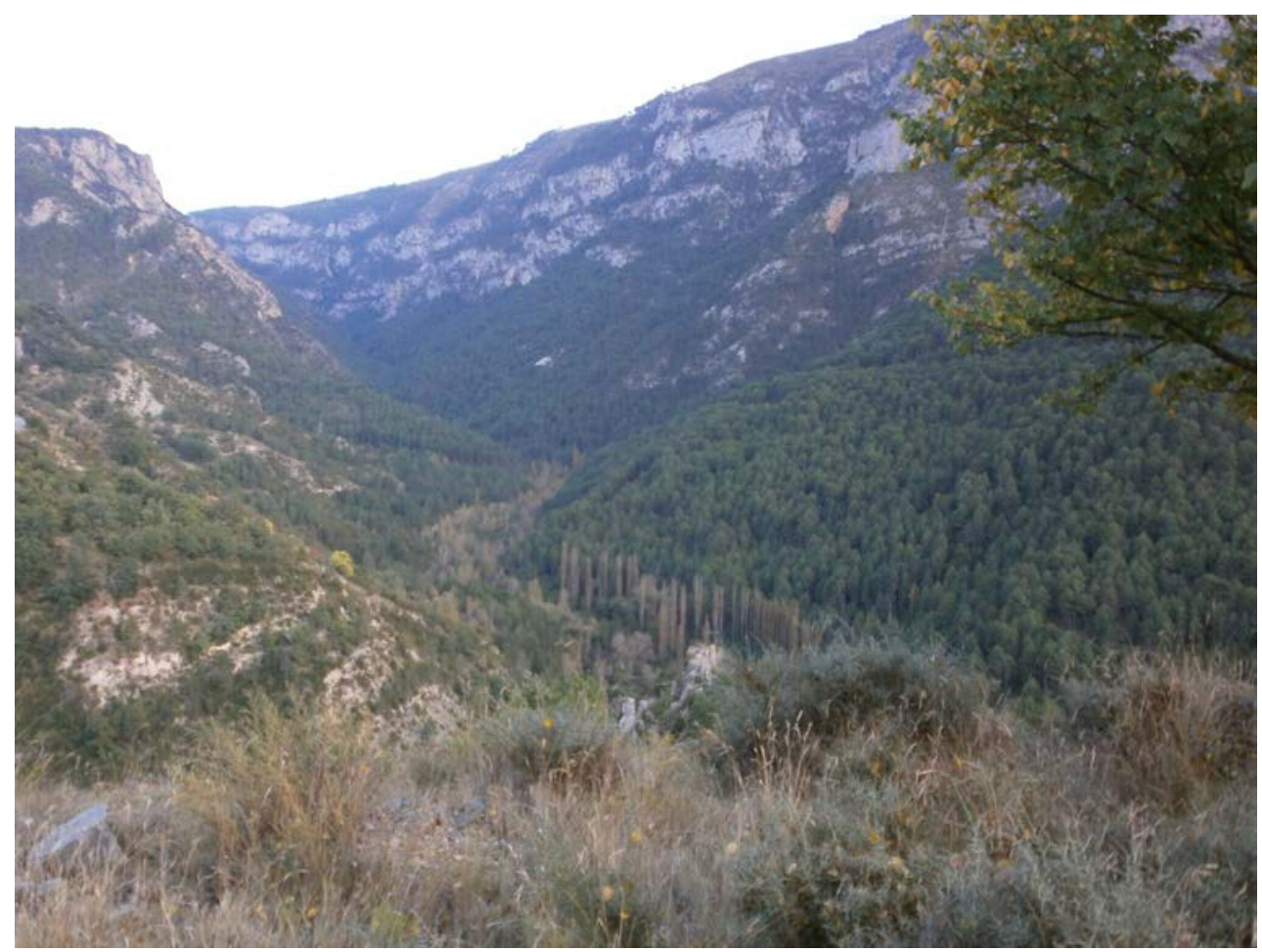

Fotografia 17. El Riu Major, prop d'Useu. A la dreta del riu es poden observar els nivells carbonatats cretàcics del Mantell de Bóixols, situats prop de Cuberes.

A l'esquerra apareixen els materials del Keuper del Mantell de les Nogueres. Octubre 2013 
Per altra banda, des d'aquesta posició, es poden veure, prop del riu, uns interessants afloraments de les calcàries cretàciques. Aquestes, com a conseqüència de l'encavalcament, es troben verticalitzades, formant uns hock-baks. (fotografia 18)

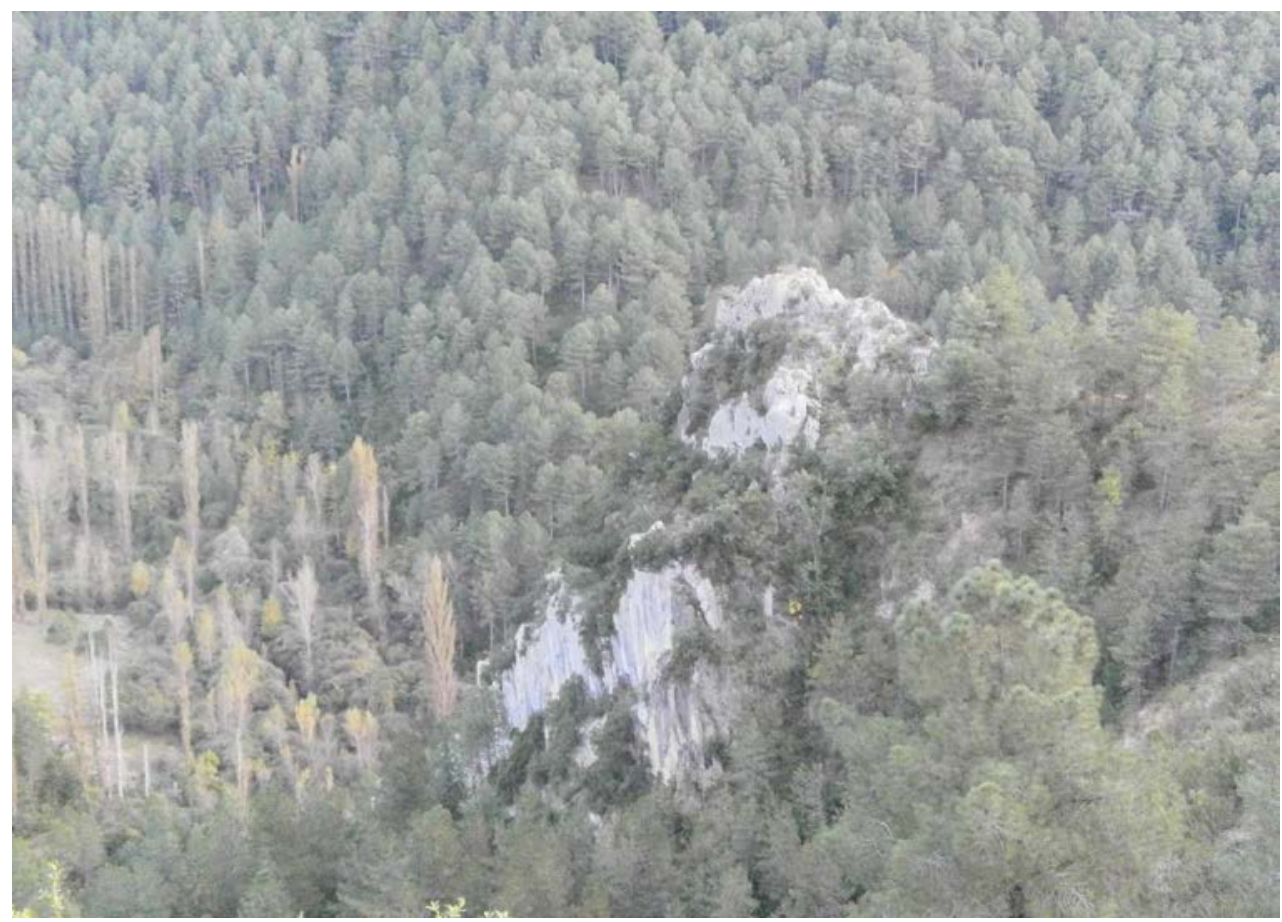

Fotografia 18. El Riu Major, prop d’Useu. A la dreta del riu es poden observar els nivells carbonatats cretàcics del Mantell de Bóixols situats en posició vertical. Octubre 2013

\subsection{Parada 14. IMMEDIACIONS TRENCALL DE BRESCA (Bresca, antic terme de Baén, actual de Gerri de la Sal - Baix Pallars). (Full 252).}

Després de fer l'aturada anterior, cal continuar cap a ponent, per tal d'arribar a les immediacions del trencall de Bresca. Quasi, e arribar-hi, farem una nova aturada, a poc menys de $1 \mathrm{~km}$ des de l'anterior parada.

En aquest recorregut, hem continuat trobant els materials esmentats als recorreguts anteriors, especialment els materials triàsics del Keuper. Així, en aquest indret hi ha un interessant aflorament d'ofites. Entre aquests materials es poden recollir molt bons exemplars d'EPIDOTA. Tanmateix es troben altres minerals, molt minoritaris, com la ZOISITA i la PREHNITA. (fotografia 19). 


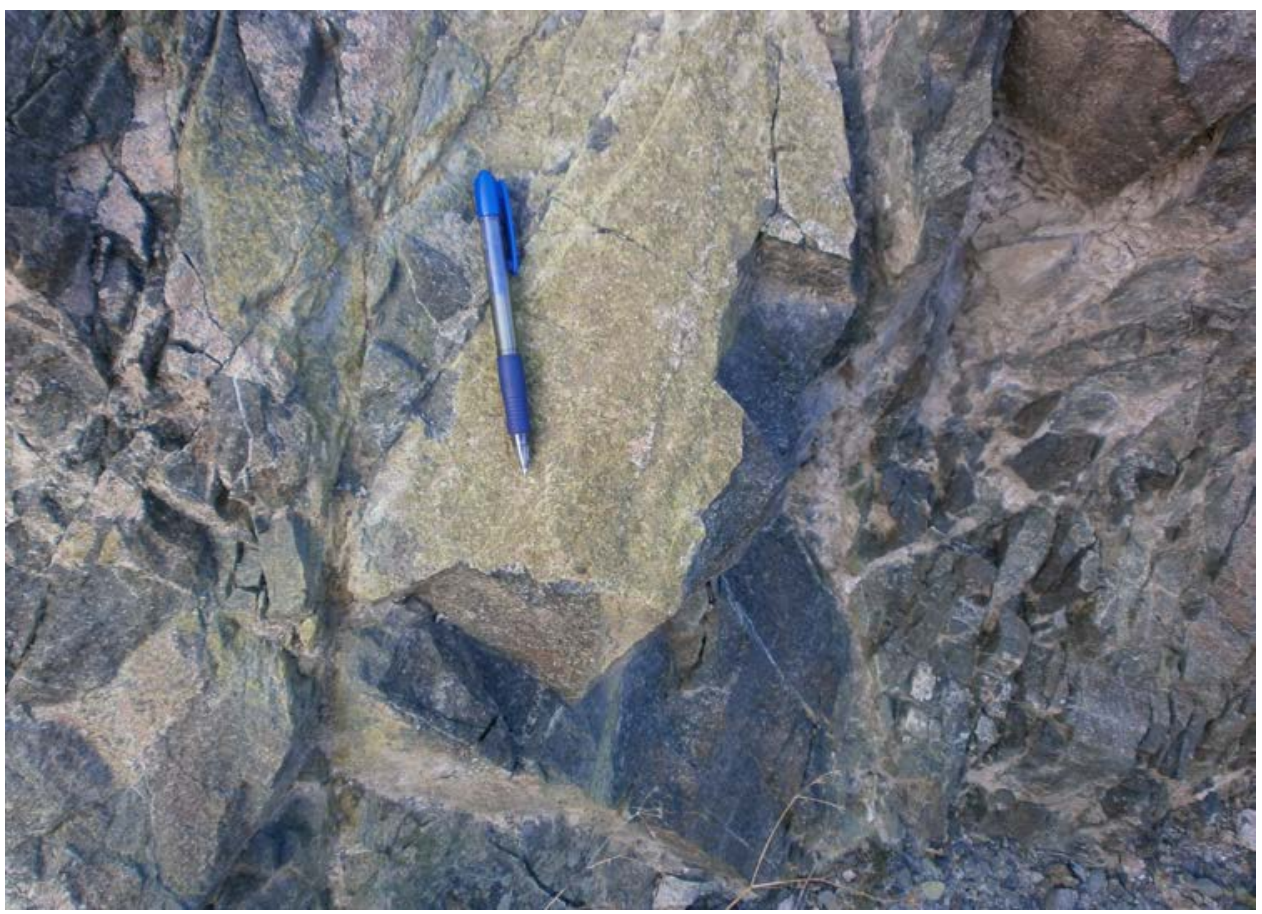

Fotografia 19. Afloraments d’EPIDOTA entre les ofites de Bresca. Octubre 2013

\subsection{Parada 15. PONT DE BRESCA (Bresca, antic terme de Gerri de la Sal, actual del de Gerri de la Sal - Baix Pallars, comarca del Pallars Sobirà). (Full 252).}

Des de la parada anterior, cal continuar cap al trencall de Bresca. Tot seguit, s'arribarà al pont sobre el Riu Noguera Pallaresa, i tot seguit a la carretera $\mathrm{N}-260$ (que en aquest indret coincideix amb l'antiga carretera comarcal C-147). Una mica mes avall del pont, a uns 50 metres anant cap a I’Estret de Collegats, s'efectuarà una breu parada, a la dreta de la carretera.

Aquest indret. es troba a uns $2 \mathrm{Km}$ del poble de Gerri de la Sal, en sentit descendent del riu i de la carretera. En aquest recorregut, s' ha passat dels afloraments dels materials carbonífers i devocions, de la Unitat de les Nogueres, als afloraments triàsics, que pertanyen a la mateixa unitat. Tot i així, a l'aturada anterior, ja havíem trobat els afloraments del Triàsic

En aquest indret es troba un aflorament dels materials ofítics del Triàsic Superior, que contenen una certa presència d'EPIDOTA. També, per d'altra banda, davant del Pont de Bresca, a l'esquerra de la carretera nacional $\mathrm{N}-260$, es poden observar uns afloraments d'uns nivells carbonats foscos. Es tracta de les calcàries triàsiques del Muschelkalk. En observar-les es troben interesants cristal-litzacions de CALCITA.

En aquest indret finalitza el recorregut de l'itinerari

Xaragall.2015 n.6 | Itinerari geològic, mineralògic i miner per les comarques de l'Alt Urgell i del Pallars Sobirà: des de la Palanca de Noves a la Guardia d’Ares, Taús, Baen, Useu i al Pont de Bresca 


\section{Bibliografia}

GUIMERÀ, J. et altri (1992).- Geologia (II), Història Natural dels Països Catalans, Vol. 2, 547 pag. Enciclopèdia Catalana, S.A. Barcelona.

MATA-PERELLÓ, J.M. (1991).- Els Minerals de Catalunya. Arxius de la Secció de Ciències de I'Institut d'Estudis Catalans, vol.47, 545 pàgines. Barcelona.

MATA-PERELLÓ, J.M. (1995).- Itinerari geològico - mineralògic per I'Alt Urgell i pel Pallars Sobirà: des de la Palanca de Noves a la Guardia d’Ares i a Bresca. Inèdit, 6 pag. Manresa

MATA-PERELLÓ, J.M. (2005).- Itinerari geològic, mineralògic i miner per les comarques de I'Alt Urgell i del Pallars Sobirà: des de la Palanca de Noves a la Guardia d'Ares i al Pont de Bresca, Gerri de la Sal i a l'Argenteria. Inèdit. 10 pàgines. Manresa.

RIBA ARDERIU, O. et altri (1976).- Geografia Física dels Països Catalans. Edit Ketres. Barcelona.

MATA-PERELLÓ, J.M. (2013).- Itinerari geològic, mineralògic i miner per les comarques de l'Alt Urgell i del Pallars Sobirà: des de la Palanca de Noves a la Guàrdia d'Ares, al Pont de Bresca i al Congost de Collegats. Inèdit. 16 pàgines. Manresa.

ROSELL SANUI, J. (1970).- Explicació del Mapa Geològic, a escala 1:50.000, corresponent al full nº 252 (Tremp). Mapa Geológico de España. Inst. Geológico y Minero de España. Madrid. 